\title{
In Silico Effects of Steviol on Depression, Inflammation and Cancer Biomarkers
}

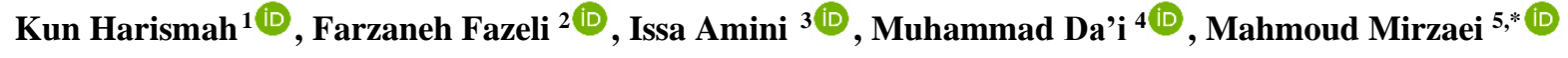 \\ 1 Department of Chemical Engineering, Faculty of Engineering, Universitas Muhammadiyah Surakarta, Surakarta, \\ Indonesia; kun.harismah@ums.ac.id (K.H.); \\ 2 Department of Biology, Payame Noor University, Tehran, Iran; seacorales@yahoo.com (F.F.); \\ 3 Department of Chemistry, Payame Noor University, Tehran, Iran; issaamini5548@ gmail.com (I.A.); \\ 4 Department of Pharmaceutical Biotechnology, Faculty of Pharmacy, Universitas Muhammadiyah Surakarta, Surakarta, \\ Indonesia; m.dai@ums.ac.id (M.D.); \\ 5 Biosensor Research Center, School of Advanced Technologies in Medicine, Isfahan University of Medical Sciences, \\ Isfahan, Iran \\ * Correspondence: mdmirzaei@pharm.mui.ac.ir (M.M.);
}

Scopus Author ID 57226521283

Received: 25.10.2021; Revised: 23.11.2021; Accepted: 26.11.2021; Published: 11.12.2021

\begin{abstract}
Steviol (ST1), a known natural product, and methylated models (ST2-ST4) were investigated in this in silico work to see their effects were examined on each of depression, inflammation, and cancer biomarkers by participating in interactions with each of monoamine oxidase-A (MAO-A), cyclooxygenase-2 (COX-2), methyltransferase (MTN) enzymes, respectably. The stabilized structures of ST1-ST4 were achieved by performing optimization calculations. Subsequently, formations of interacting ligand-target complexes were examined by molecular docking (MD) simulations. The evaluated molecular orbital features showed a different tendency of ST1-ST4 models for contributing to electron transfer processes. Accordingly, the interacting ligand-target complexes showed differential interactions of each ligand towards each target, making ST1-ST4 as appropriate compounds for the detection of targets. The methylated ST2-ST4 models worked even better than the original ST1 model to affirm the benefit of steviol modification to achieve desired results. Meaningful interactions of ST1ST4 with the targets also showed the possible application of steviol for the medication of each of depression, inflammation, and cancer cases.
\end{abstract}

Keywords: steviol; depression; inflammation; cancer; molecular docking; in silico.

(C) 2021 by the authors. This article is an open-access article distributed under the terms and conditions of the Creative Commons Attribution (CC BY) license (https://creativecommons.org/licenses/by/4.0/).

\section{Introduction}

Natural products have always been used as complementary food materials in addition to their long-time roles in traditional medicine [1-3]. In this regard, several attempts have been dedicated to characterizing the features of such natural products besides developing their synthesis procedures in laboratories [4-6]. Moreover, exploring new functions for such related compounds has also been an important task regarding drug design, discovery, and developments [7-9]. Indeed, so many available pharmaceutical compounds have been generated from the already available natural products, which leads to further investigations for increasing knowledge about the topic of applications of natural products in living systems [1012]. Steviol (Figure 1) is a known natural product isolated from the Stevia rebaudiana plant, which could be used as a sweet compound instead of sugar [13-15]. Earlier works have investigated the bioactivity of steviol, showing the importance of this compound for applications in living systems [16-18]. Various types of research works have been performed https://biointerfaceresearch.com/ 
on the issue of steviol to this time to show their features for employing in living systems [19]. Accordingly, the effects of steviol on depression, inflammation, and cancer biomarkers have been investigated in this work based on employing the in silico approach for solving problems in science and technology [20-22]. Indeed, combinations of mathematical algorithms and theoretical approaches could help provide a useful tool for investigating the materials at the smallest scales. The tool has been seen applicable for doing such issues by performing computer-based works [23-25].

Biomarkers have dual importance in recognizing and managing diseases in living systems [26-28]. In this regard, providing useful tools for detecting such biomarkers could also help to medicate them, especially in the early stages of disease progression [29-31]. To achieve such a purpose, examining the benefits of the natural product is an important issue regarding the development of new pharmaceutical compounds [32-34]. In this work, monoamine oxidase-A (MAO-A), cyclooxygenase-2 (COX-2), and methyltransferase (MTN) were employed as biomarkers of depression, inflammation, and cancer to interact with the steviol compound [35-37]. Indeed, complex formations of interacting ligand-target systems were investigated for achieving the purpose of detection and medication of biomarkers with the assistance of the ST compounds. In this regard, earlier works indicated that the investigation of interacting substances could help recognize the effects of such complex formations on features of each substance counterpart [38-40]. To this aim, computation on individual ST ligand structures was performed first, and their interactions by performing molecular docking (MD) simulations were examined next. Consequently, the effects of steviol ligands on each of MAOA, COX-2, and MTN targets were investigated to show the potency of this natural product for further application in living systems. For more clarifying the purpose of this work, it could be mentioned that the model of a natural product was investigated towards three biomarkers to find possible interacting complex formations of the models. The in silico work was employed to obtain the required information for discussing the current purpose.
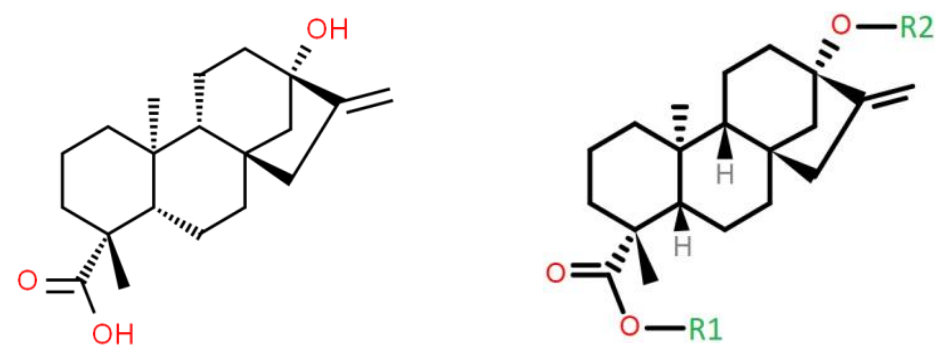

Figure 1. Steviol (left) and its derivatives representation (right).

\section{Materials and Methods}

As described in Table 1, the geometers of four steviol models (ST1-ST4) were optimized by employing the semi-empirical PM3 method as included in the Gaussian program [41]. After doing this step, ligand structures were prepared for further analysis regarding their specifications, in addition to examining their interactions with the specified targets. ZINDO calculations were performed on the already optimized ST1-ST4 compounds to evaluate their molecular orbital features, including HOMO and LUMO implying for the highest occupied and the lowest unoccupied molecular orbitals, EG implying for energy gap, $\mathrm{H}$ and $\mathrm{S}$ implying for chemical hardness and softness, and DM implying for dipole moment, which were all listed in Table 1. Additionally, representations of HOMO-LUMO distribution patterns were visualized for the optimized ligands, as shown in Figure 2. As a consequence, the ligands' specifications 
and descriptions were evaluated to show their original features prior to their involvement in interactions with the target. Next, 3D macromolecular structures of each of MAO-A (2z5y), COX-2 (3ln1), and MTN (4x61) enzymes were obtained from the protein data bank [42] to be designated for the target compounds of molecular docking (MD) simulations. For performing accurate MD simulations, ligands and targets were submitted to the SwissDock web server [43]. Each of the interacting ST ligands and MAO-A, COX-2, and MTN targets were examined for complex formations in a defined $40 * 40 * 40$ grid box. As a result, values of $\Delta \mathrm{G}$ for showing the strength of ligand-target complexes and values of RMSD for showing structural variations of ligands from beginning up to completing the MD simulation processes were evaluated in addition to representation of surrounding amino acids of centralized ligand (Figure 3). To this point, the effects of ST ligands on each of MAO-A, COX-2, and MTN targets, implying depression, inflammation, and cancer biomarkers, were calculated for providing information to achieve the goal of this work.

Table 1. Molecular descriptors for the optimized models.

\begin{tabular}{c|c|c|c|c|c|c|c|c} 
& R1 & R2 & HOMO eV & LUMO eV & EG eV & H eV & S eV $^{-1}$ & DM Debye \\
\hline ST1 & H & H & -9.14 & 0.59 & 9.73 & 4.86 & 0.20 & 7.79 \\
\hline ST2 & Me & H & -9.09 & 0.62 & 9.71 & 4.85 & 0.21 & 7.68 \\
\hline ST3 & H & Me & -9.04 & 0.63 & 9.67 & 4.83 & 0.21 & 7.57 \\
\hline ST4 & $\mathrm{Me}$ & $\mathrm{Me}$ & -9.01 & 0.68 & 9.69 & 4.84 & 0.21 & 7.48
\end{tabular}

\section{Results and Discussion}

This work's main goal was to investigate the effects of steviol (Figure 1) on depression, inflammation, and cancer biomarkers based on employing the in silico approach. To this aim, four models of steviol, including ST1-ST4, were designed by methylation (Me) of hydroxyl groups of the structure, as described in Table 1. As a result, ligands were obtained based on optimization processes to reach the minimized energy structures. Afterward, their molecular orbital features were evaluated. At this step, the results of Table 1 could show that the evaluated descriptors of models detected effects of the methyl group addition by changes of values of features compared to each other. Both HOMO and LUMO levels underwent changes in energy levels, in which their energy differences also detected the effects of such changes of frontier molecular orbitals. It is worth mentioning here that each of HOMO and LUMO levels could be designated for possible levels of electron transfer processes, in which HOMO could imply for that of electron-donating level, and LUMO could imply for that of electron-accepting level. In this case, variations of such levels could change the electronic features of the models for contributing to both internal and external electron transfer processes. Accordingly, values of EG could help to know the distance of HOMO and LUMO levels for the internal electron transferring process. The results indicated that St1-ST4 models showed different features regarding the energy vales of HOMO and LUMO levels with a reduction of energy distance between the two levels in the methylated group. This reduction could help to proceed internal electron transferring process easier, in which values of chemical hardness and softness $(\mathrm{H}$ and S) could affirm this issue. In the case of the contribution of a compound to reaction processes, both $\mathrm{H}$ and $\mathrm{S}$ features could help predict the purpose. Smaller $\mathrm{H}$ and larger values of $\mathrm{S}$ could be suitable for substance participation in the reaction processes. 


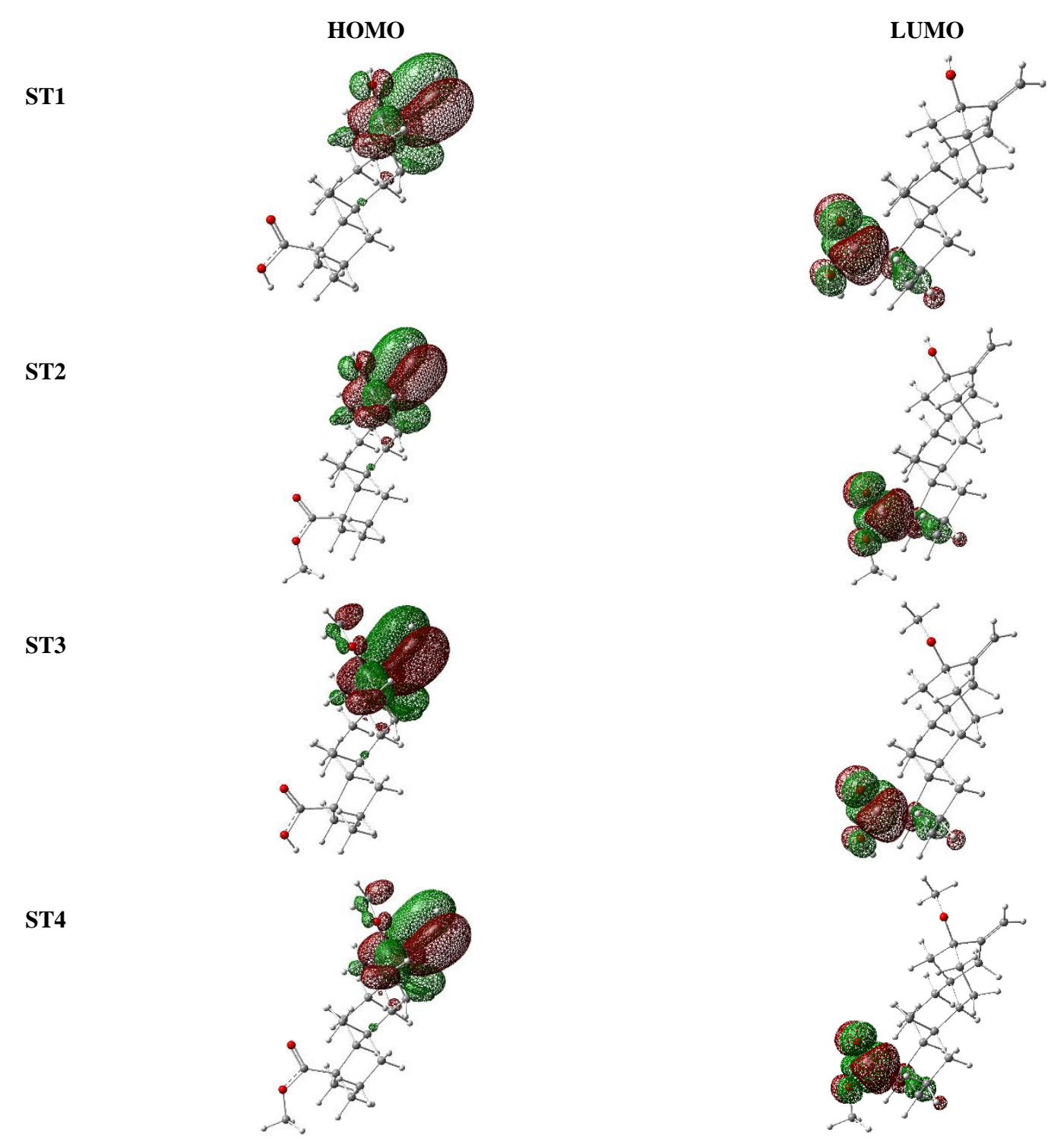

Figure 2. Visualized HOMO-LUMO distribution patterns and ESP surfaces.

Visualized HOMO-LUMO distribution patterns (Figure 2) also showed slight variations of molecular orbital patterns among the models. As an important point for such HOMO-LUMO patterns, they were localized at opposite sides of the molecule, making it suitable for interaction with other substances. In this regard, notable dipole moment (DM) values could affirm such typical HOMO-LUMO distribution patterns for ST1-ST4 ligand models. As a consequence, stabilized structures of ST1-ST4 ligand models were obtained, and their frontier molecular orbital features were analyzed for making a description of such ligand systems for involving in interactions.

To examine the effects of each of ST1-ST4 ligands on each of depression, inflammation, and cancer biomarkers, formations of interacting ligand-target complexes were investigated by performing MD simulations. In this case, MAO-A, COX-2, and MTN enzymes were located at the position of the target for involvement in interaction processes. To do this, the results of energy strength of formations of such interactions were evaluated in addition to the conformational location of centralized ligand among the surrounding amino acids. The obtained results were represented in Figure 3 to show surrounding amino acids and energy strengths. Moreover, conformational variations of ligands from the start point to the endpoint of MD simulations were summarized in the term of RMSD, meaning the magnitude of such variation. 
Consequently, the models were summarized through quantitative and qualitative descriptions to achieve the goal of this work to see the effects of ST ligands on the specified targets. As a benefit of performing in silico works, details of interactions could be achieved very well for the investigated systems.

\begin{tabular}{|c|c|c|c|}
\hline & МАО-А & COX-2 & MTN \\
\hline ST1 & 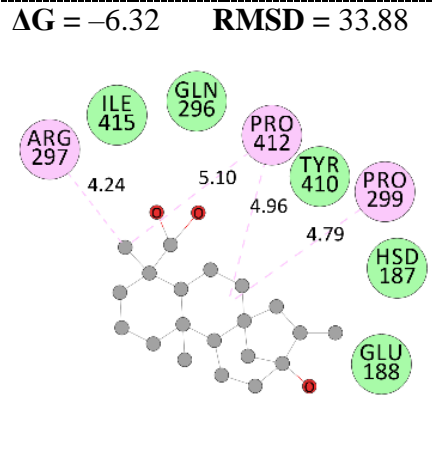 & 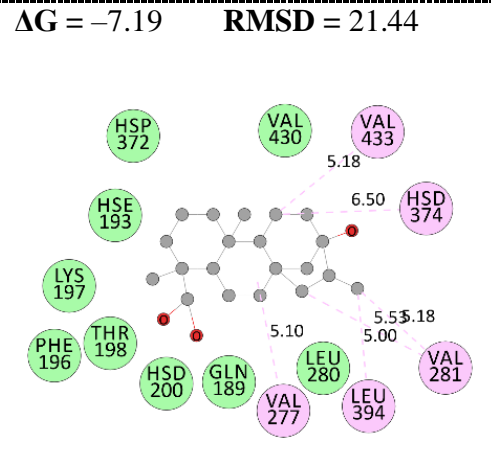 & 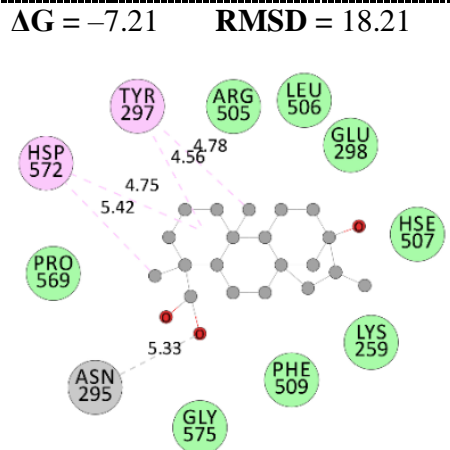 \\
\hline ST2 & 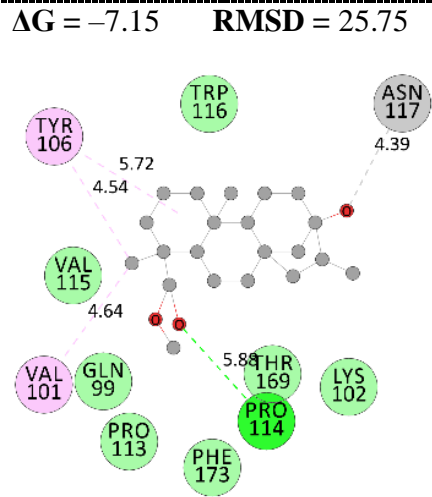 & 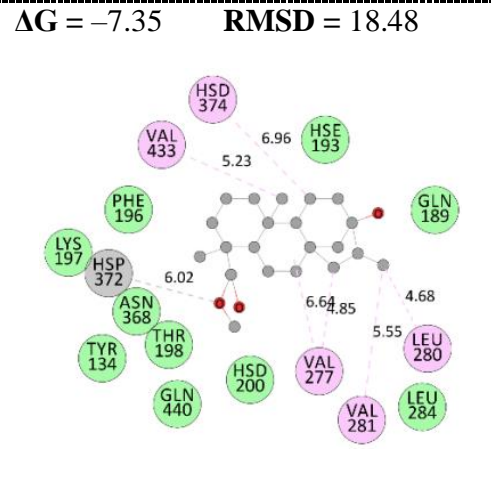 & 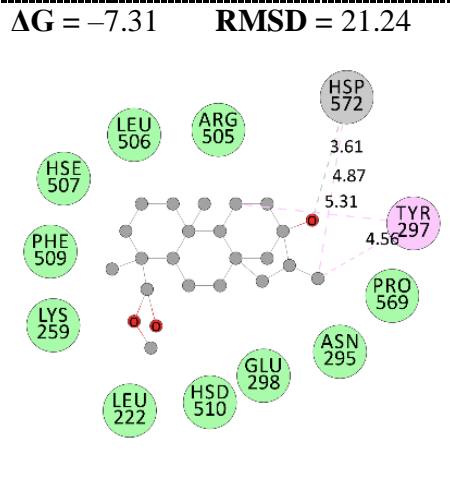 \\
\hline ST3 & 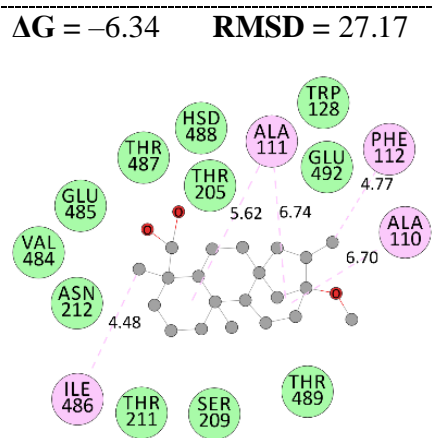 & 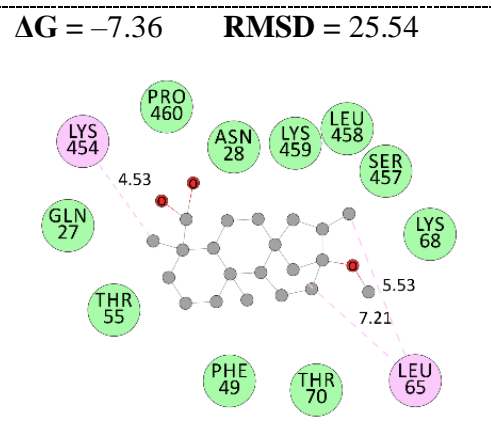 & 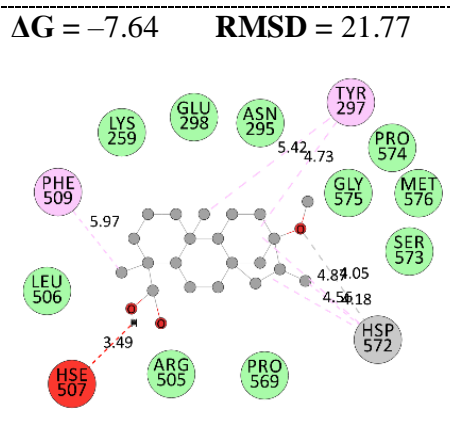 \\
\hline ST4 & 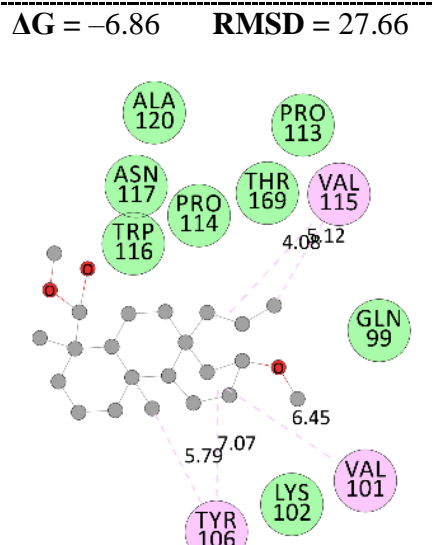 & 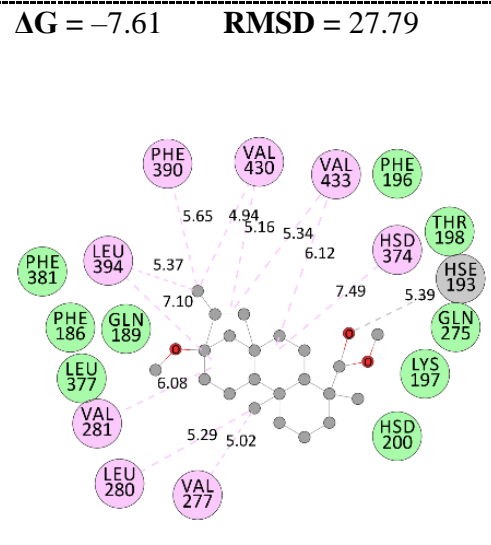 & 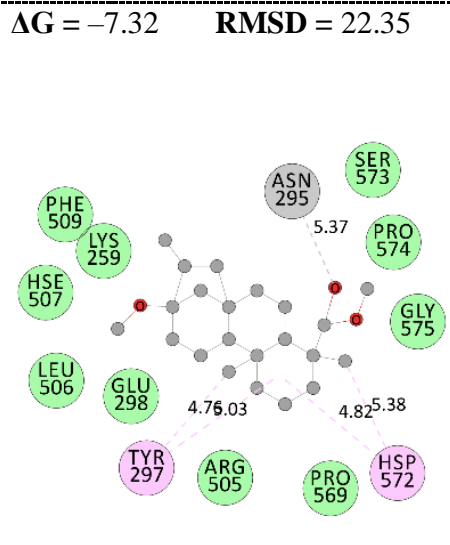 \\
\hline
\end{tabular}

Figure 3. Interacting ligand-target complexes. 
Comparing the obtained results of Figure 3 could show quick achievements regarding the importance of the initial hypothesis about proposing methylated steviol models. The strengths of those interacting ST2-ST4 ligands with the targets were more significant than the original ST1 ligand. Moreover, the strength of each ligand towards targets was different, showing a differential diagnosis of ligand for a specified target. In this regard, two main points could be concluded; first, ST2-ST4 ligands could work better than ST1, and second, a differential diagnosis could be occurred by employing a ligand towards different targets. As mentioned before, two purposes of detection and medication could be explored for the ligands through formations of interacting ligand-target complex systems, as could be seen by the differential diagnosis of ST1-ST4 towards MAO-A, COX-2, and MTN targets. More analysis of the obtained complex models could lead to some achievements regarding the importance of $\Delta \mathrm{G}$ and RMSD values for the characterization of the models. In addition, the surrounding amino acids and types of interactions were other important achievements of this work. On a quick note, steviol could be considered a possible ligand for participating in interactions with the specified targets. However, careful analysis of the models could distinguish steviol compounds with specificity towards each target. By the obtained results, ST2 could be considered for selective interaction with MAO-A, ST4 could be considered for selective interaction with COX-2, and ST3 could be considered for selective interaction with MTN targets regarding their calculated effects on depression, inflammation, and cancer biomarkers. This achievement shows the importance of structural modifications for obtaining desired ligands, in which each ligand could work its role in the living systems. Indeed, lead optimization is an important procedure of drug design techniques. Steviol was considered a lead compound to be optimized for participating in differential interaction with MAO-A, COX-2, and MTN targets. Comparing with other related works could show that the investigated steviol could be considered an appropriate candidate for the complementary medication of such depression, inflammation, and cancer cases [44-46].

\section{Conclusions}

Effects of steviol compounds on each of depression, inflammation, and cancer biomarkers were investigated in this work by examining formations of interacting methylated ligands of steviol towards each of MAO-A, COX-2, and MTN enzyme targets. In this regard, optimized models of ligands were obtained, and their features were evaluated in singular forms and interactions with the target models. The achievements of this work can be summarized as follows. First, methylated steviol compounds (ST2-ST4) showed geometrical stability in addition to the original one (ST1), and their molecular features indicated differences in their contribution to electron transfer processes. Second, both internal and external contributions of ST1-ST4 ligands to electron transferring processes detected the effects of methylation. Third, each ligand showed different stability towards the specified target, making them appropriate structures for diagnosing biomarkers. Fourth, the methylated ST2-ST4 ligands worked better than the original ST1 ligand in all cases $\mathrm{f}$ interactions showing the importance of lead optimization to obtain new steviol compounds with specificity towards the enzyme target. And as a final note, the proposed ST1-ST4 ligands could work for detection purposes by their different strengths of interacting complex formations. They could also work for medication purposes by their meaningful contribution to interactions with the target enzymes. 


\section{Funding}

This research received grant no. (299093) from the research council of the Isfahan University of Medical Sciences.

\section{Acknowledgments}

Mahmoud Mirzaei acknowledges the support of this work by the research council of the Isfahan University of Medical Sciences.

\section{Conflicts of Interest}

\section{The authors declare no conflict of interest.}

\section{References}

1. Mani, J.S.; Johnson, J.B.; Steel, J.C.; Broszczak, D.A.; Neilsen, P.M.; Walsh, K.B.; Naiker, M. Natural product-derived phytochemicals as potential agents against coronaviruses: a review. Virus Research 2020, 284, 197989, https://doi.org/10.1016/j.virusres.2020.197989.

2. Ma, X.; Zhang, W.; Jiang, Y.; Wen, J.; Wei, S.; Zhao, Y. Paeoniflorin; a natural product with multiple targets in liver diseases - a mini review. Frontiers in Pharmacology 2020, 11, 531, https://doi.org/10.3389/fphar.2020.00531.

3. Harismah, K.; Fazeli, F.; Zandi, H. Structural analyses of vanillin derivative compounds and their molecular docking with mpro and rdrp enzymes of covid-19. Biointerface Research in Applied Chemistry 2022, 12, 1660-1669, https://doi.org/10.33263/BRIAC122.16601669.

4. Da'I, M.; Wahyuni, A.S.; Ika Trisharyanti, D.K.; Azizah, T.; Suhendi, A.; Saifudin, A. Antioxidant activity of Phyllanthus niruri L. herbs: in vitro and in vivo models and isolation of active compound. National Journal of Physiology, Pharmacy and Pharmacology 2016, 6, 32-37, https://doi.org/10.5455/njppp.2015.5.0510201575.

5. Da'I, M.; Wikantyasning, E.R.; Suhendi, A.; Hairunisa I. Validated HPLC method for determination of andrographolide in mixed herbal extract. International Journal of Pharmaceutical Sciences Review and Research 2015, 35, 140-143.

6. Da'I, M.; Suhendi, A.; Meiyanto, E.; Jenie, U.A.; Kawaichi, M. Apoptosis induction effect of curcumin and its analogs pentagamavunon- 0 and pentagamavunon-1 on cancer cell lines. Asian Journal of Pharmaceutical and Clinical Research 2017, 10, 373-376, https://doi.org/10.22159/ajpcr.2017.v10i3.16311.

7. Akram, M.; Siddique, A.; Laila, U.; Ghotekar, S.; Pagar, K.; Oza, R. Traditional use, phytochemistry and pharmacology of Genus sesbania: a review. Advanced Journal of Science and Engineering 2021, 2, 64-68, https://doi.org/10.22034/advjscieng21021064.

8. Zandi, H.; Harismah, K. Computer-based tools for structural characterizations and activity specifications of natural products: a quick review. Lab-in-Silico 2021, 2, 50-54, https://doi.org/10.22034/labinsilico21021050.

9. Ghanadian, M.; Ali, Z.; Khan, I.A.; Balachandran, P.; Nikahd, M.; Aghaei, M.; Mirzaei, M.; Sajjadi, S.E. A new sesquiterpenoid from the shoots of Iranian Daphne mucronata Royle with selective inhibition of STAT3 and Smad3/4 cancer-related signaling pathways. DARU Journal of Pharmaceutical Sciences 2020, 28, 253262, https://doi.org/10.1007/s40199-020-00336-x.

10. Idris, M.O.; Adeniji, S.E.; Habib, K.; Adeiza A.A. Molecular docking of some novel quinoline derivatives as potent inhibitors of human breast cancer cell line. Lab-in-Silico 2021, 2, 30-37, https://doi.org/10.22034/labinsilico21021030.

11. Mirzaei, M.; Harismah, K.; Soleimani, M.; Mousavi, S. Inhibitory effects of curcumin on aldose reductase and cyclooxygenase-2 enzymes. Journal of Biomolecular Structure and Dynamics 2021, 39, 6424-6430, https://doi.org/10.1080/07391102.2020.1800513.

12. Maryati, M.; Saifudin, A.; Wahyuni, S.; Rahmawati, J.; Arrum, A.; Priyunita, O.; Aulia, A.; Putra, F.P.; As'hari, Y.; Rasyidah, U.M.; Fadhilah, A. Cytotoxic effect of Spirulina platensis extract and Ulva compressa Linn. on cancer cell lines. Food Research 2020, 4, 1018-1023, https://doi.org/10.26656/fr.2017.4(4).389. 
13. Castro-Muñoz, R.; Díaz-Montes, E.; Cassano, A.; Gontarek, E. Membrane separation processes for the extraction and purification of steviol glycosides: an overview. Critical Reviews in Food Science and Nutrition. 2020, 61, 2152-2174, https://doi.org/10.1080/10408398.2020.1772717.

14. Harismah, K.; Ariningrum, N.D.; Fuadi, A.M.; Mujiburohman, M.; Mirzaei, M. Formulation and evaluation of herbal hand sanitizer based on stevia (Stevia rebaudiana). Journal of Physics: Conference Series 2021, 1858, 012053, https://doi.org/10.1088/1742-6596/1858/1/012053.

15. Meesschaert, B.; Moons, N.; Steurs, G.; Monballiu, A.; Amery, R.; Jooken, E.; Geuns, J. Degradation of steviol glycosides via steviol and Monicanone by soil microorganisms and UASB effluent. Journal of Environmental Chemical Engineering 2021, 9, 106342, https://doi.org/10.1016/j.jece.2021.106342.

16. Libik-Konieczny, M.; Capecka, E.; Tuleja, M.; Konieczny, R. Synthesis and production of steviol glycosides: recent research trends and perspectives. Applied Microbiology and Biotechnology 2021, 105, 3883-3900, https://doi.org/10.1007/s00253-021-11306-X.

17. Voloshina, A.D.; Sapunova, A.S.; Kulik, N.V.; Belenok, M.G.; Strobykina, I.Y.; Lyubina, A.P.; Gumerova, S.K.; Kataev, V.E. Antimicrobial and cytotoxic effects of ammonium derivatives of diterpenoids steviol and isosteviol. Bioorganic \& Medicinal Chemistry 2021, 32, 115974, https://doi.org/10.1016/j.bmc.2020.115974.

18. Ozdemir, T.; Ozcan, T. Effect of steviol glycosides as sugar substitute on the probiotic fermentation in milk gels enriched with red beetroot (Beta vulgaris L.) bioactive compounds. LWT 2020, 134, 109851, https://doi.org/10.1016/j.lwt.2020.109851.

19. Gunasena, M.D.; Senarath, R.M.; Senarath, W.T. A review on chemical composition, biosynthesis of steviol glycosides, application, cultivation, and phytochemical screening of Stevia rebaudiana (Bert.) bertoni. Journal of Pharmaceutical Research International 2021, 33, 85-104, https://doi.org/10.9734/jpri/2021/v33i29B31593.

20. Sabe, V.T.; Ntombela, T.; Jhamba, L.A.; Maguire, G.E.; Govender, T.; Naicker, T.; Kruger, H.G. Current trends in computer aided drug design and a highlight of drugs discovered via computational techniques: a review. European Journal of Medicinal Chemistry 2021, 224, 113705, https://doi.org/10.1016/j.ejmech.2021.113705.

21. Ashjaee, Y.; Zandi, H. Molecular analysis of 5-COR derivatives of uracil and evaluating their affinity against the MPro target of COVID-19. Advanced Journal of Science and Engineering 2021, 2, 79-85, https://doi.org/10.22034/advjscieng21022079.

22. Mirzaei, M.; Hadipour N.; Gulseren O. DNA codon recognition by a cubane wire: in silico approach. Turkish Computational and Theoretical Chemistry 2021, 5, 13-19, https://doi.org/10.33435/tcandtc.828634.

23. Shirazi, Z.; Khakdan, F. In silico genome-wide identification and characterization of glutathione peroxidase gene family in wild cherries (Prunus avium L). Journal of Plant Bioinformatics and Biotechnology 2021, 1, 60-72, http://doi.org/10.22034/jpbb.2021.289018.1008.

24. Sardoei, A.S.; Rezaei, H.; Ghasemi, H. In silico evaluation of expansin-gene function in softening and fruit ripening. Journal of Plant Bioinformatics and Biotechnology 2021, 1, 73-83, http://doi.org/10.22034/jpbb.2021.302209.1014.

25. Zare, A.; Mirzaei, M.; Rostami, M.; Jafari, E. Photosensitization of phthalocyanine for singlet oxygen generation in photodynamic therapy applications. Journal of Medicinal and Chemical Sciences 2020, 3, 5559, http://doi.org/10.26655/JMCHEMSCI.2020.1.7.

26. Davis, K.D.; Aghaeepour, N.; Ahn, A.H.; Angst, M.S.; Borsook, D.; Brenton, A.; Burczynski, M.E.; Crean, C.; Edwards, R.; Gaudilliere, B.; Hergenroeder, G.W. Discovery and validation of biomarkers to aid the development of safe and effective pain therapeutics: challenges and opportunities. Nature Reviews Neurology 2020, 16, 381-400, https://doi.org/10.1038/s41582-020-0362-2.

27. Soleimani, M.; Mirzaei, M.; Mofid, M.R.; Khodarahmi, G.; Rahimpour, S.F. Lactoperoxidase inhibition by tautomeric propylthiouracils. Asian Journal of Green Chemistry 2020, 4, 1-10, https://doi.org/10.22034/AJGC/2020.1.1.

28. Karimzadeh Jouzdani, M., Karimzadeh Jouzdani, M., Mohebbi, B. The role of inflammatory biomarkers in predicting in-stent restenosis. Journal of Medicinal and Chemical Sciences 2021, 4, 635-645, https://doi.org/10.26655/JMCHEMSCI.2021.6.12.

29. Leva-Bueno, J.; Peyman, S.A.; Millner, P.A. A review on impedimetric immunosensors for pathogen and biomarker detection. Medical Microbiology and Immunology 2020, 209, 343-362, https://doi.org/10.1007/s00430-020-00668-0. 
30. Mirkamali ES, Ahmadi R. Adsorption of melphalan anticancer drug on the surface of boron nitride cage (B12N12): A comprehensive DFT study. Journal of Medicinal and Chemical Sciences 2020, 3, 199-207, https://doi.org/10.26655/JMCHEMSCI.2020.3.1.

31. Mohammadi, S.; Doustkhah, E.; Salehi Chaleshtori, A.; Esmailpour, M.; Zamani, F.; Esmailpour, A. A computational study at blocking probability of the SARS-CoV-2 spike protein through the binding of cellular receptors. Eurasian Chemical Communications 2021, 3, 369-382, https://doi.org/10.22034/ecc.2021.277176.1146.

32. Atanasov, A.G.; Zotchev, S.B.; Dirsch, V.M.; Supuran, C.T. Natural products in drug discovery: advances and opportunities. Nature Reviews Drug Discovery 2021, 20, 200-216, https://doi.org/10.1038/s41573-02000114-z.

33. Baghernejad, B.; Salimifar, S. A simple and environmentally benign method for the synthesis of bis (4hydroxycoumarin) methane derivatives using Nano-CeO2. Asian Journal of Green Chemistry 2021, 5, 196205, https://doi.org/10.22034/ajgc.2021.129214.

34. Madadi, Z.; Soltanieh, M.; Bagheri Lotfabad, T.; Sohrabi Nazari, B. Green synthesis of titanium dioxide nanoparticles with Glycyrrhiza glabra and their photocatalytic activity. Asian Journal of Green Chemistry 2020, 4, 256-268, https://doi.org/10.22034/AJGC/2020.3.3.

35. Uzbekov, M.G. Monoamine oxidase as a potential biomarker of the efficacy of treatment of mental disorders. Biochemistry 2021, 86, 773-783, https://doi.org/10.1134/S0006297921060146.

36. Szweda, M.; Rychlik, A.; Babińska, I.; Pomianowski, A. Cyclooxygenase-2 as a biomarker with diagnostic, therapeutic, prognostic, and predictive relevance in small animal oncology. Journal of Veterinary Research 2020, 64, 151-160, https://doi.org/10.2478/jvetres-2020-0018.

37. Hassona, M.M.; Naguib, M.; Radwan, E.M.; Abdel-Samiee, M.; Estaphan, S.; Abdelsameea, E. DNA methyltransferases as potential biomarkers for HCV related hepatocellular carcinoma. Asian Pacific Journal of Cancer Prevention 2020, 21, 3357-3363, https://doi.org/10.31557/APJCP.2020.21.11.3357.

38. Alghamdi, S.; Asif, M. Pyridazine derivatives act as phosphodiesterase-III, IV, and V Inhibitors. Journal of Applied Organometallic Chemistry 2021, 1, 116-124, http:// doi.org/10.22034/jaoc.2021.289851.1024.

39. Harismah, K.; Mirzaei, M.; Dai, M.; Roshandel, Z.; Salarrezaei, E. In silico investigation of nanocarbon biosensors for diagnosis of COVID-19. Eurasian Chemical Communications 2021, 3, 95-102, https://doi.org/10.22034/ecc.2021.267226.1120.

40. Mirzaei, M.; Gulseren, O.; Rafienia, M.; Zare, A. Nanocarbon-assisted biosensor for diagnosis of exhaled biomarkers of lung cancer: DFT approach. Eurasian Chemical Communications 2021, 3, 154-161, https://doi.org/10.22034/ecc.2021.269256.1126.

41. Frisch.; M.J.; Trucks.; G.W.; Schlegel.; H.B.; Scuseria.; G.E.; Robb.; M.A.; Cheeseman.; J.R.; Scalmani.; G.; Barone.; V. \& al. Gaussian 09. Gaussian.; Inc..; Wallingford.; CT 2009.

42. Goodsell, D.S.; Zardecki, C.; Di Costanzo, L.; Duarte, J.M.; Hudson, B.P.; Persikova, I.; Segura, J.; Shao, C.; Voigt, M.; Westbrook, J.D.; Young, J.Y. RCSB Protein Data Bank: enabling biomedical research and drug discovery. Protein Science 2020, 29, 52-65, https://doi.org/10.1002/pro.3730.

43. Patil, N.S.; Rohane, S.H. Organization of Swiss Dock: in study of computational and molecular docking study. Asian Journal of Research in Chemistry 2021, 14, 145-148, https://doi.org/10.5958/09744150.2021.00027.4.

44. Mirzaei, M.; Nazemi, H. In silico interactions between curcumin derivatives and monoamine oxidase-a enzyme. Biointerface Research in Applied Chemistry 2022, 12, 3752-3761, https://doi.org/10.33263/BRIAC123.37523761.

45. Alfayomy, A.M.; Abdel-Aziz, S.A.; Marzouk, A.A.; Shaykoon, M.S.; Narumi, A.; Konno, H.; Abou-Seri, S.M.; Ragab, F.A. Design and synthesis of pyrimidine-5-carbonitrile hybrids as COX-2 inhibitors: Antiinflammatory activity, ulcerogenic liability, histopathological and docking studies. Bioorganic Chemistry 2021, 108, 104555, https://doi.org/10.1016/j.bioorg.2020.104555.

46. Ghamsari, P.A.; Samadizadeh, M.; Mirzaei, M. Halogenated derivatives of cytidine: structural analysis and binding affinity. Journal of Theoretical and Computational Chemistry 2020, 19, 2050033, https://doi.org/10.1142/S0219633620500339. 